\title{
TBX22 mutations are a frequent cause of cleft palate
}

\author{
A C B Marçano, K Doudney, C Braybrook, R Squires, M A Patton, M M Lees, A Richieri-Costa, \\ A C Lidral, J C Murray, G E Moore, P Stanier
}

J Med Genet 2004;41:68-74. doi: 10.1136/jmg.2003.010868

$\mathrm{C}$ left lip and/or cleft palate is among the most frequent birth defect seen in humans, with a reported prevalence of 1 in 700 births worldwide. ${ }^{1}$ Development of the secondary palate is a complex coordinated sequence of events, beginning with the appearance of palatal shelves from the first branchial arch derived maxillary prominences during the sixth week of embryogenesis. This involves mesenchymal-epithelial interactions, cell differentiation, migration, and transformation, with the interactive role of soluble growth factors, extracellular matrix molecules and their receptors, and programmed cell death. ${ }^{23}$ A disruption anywhere in the required sequence may result in a failure of the palate to close.

A genetic involvement in clefts was first recognised by Fogh-Anderson, ${ }^{4}$ with the majority of cases thought to display a multifactorial mode of inheritance. ${ }^{5}$ Analysis of recurrence risk patterns of cleft lip with or without cleft palate $(\mathrm{CL} / \mathrm{P})$ indicates that there are likely to be few major loci interacting epistatically with an oligogenic background. ${ }^{6} 7$ As a consequence, there have been numerous studies to identify genetic determinants, either studying individual candidate genes and loci, ${ }^{8}$ or screening at the whole genome level. ${ }^{10-12}$ These efforts have been encouraged by the many candidates revealed by mouse mutants that exhibit a cleft as at least part of their phenotype. ${ }^{13}$ Nevertheless, the results of many of these studies have not been informative, with only a few candidate genes or loci being strongly implicated in human $\mathrm{CL} / \mathrm{P}$ or $\mathrm{CP}$ only. ${ }^{12}$ As a consequence, the mechanisms of interaction, which probably include both genes and the environment, remain poorly understood. Recently, however, significant progress has been made with the identification of gene mutations in several forms of $\mathrm{CL} / \mathrm{P}$ and $\mathrm{CP}$. These include the cell adhesion molecule $P V R L 1^{14}$ and the transcription factors MSXI, IRF6, and TBX22. ${ }^{15-19}$

TBX22 encodes a $T$ box containing transcription factor that is mutated in families with X-linked cleft palate including ankyloglossia (CPX; OMIM 303400)..$^{18}$ CPX has been described in a small number of families exhibiting a strong $X$ linked Mendelian inheritance. ${ }^{20-27}$ The cleft phenotype predominantly affects males who show variation ranging from a complete cleft of the secondary palate, submucous cleft, or bifid uvula to high arched palate. Ankyloglossia (tongue tie) is frequently seen in affected patients and carrier females, ${ }^{28}$ and has proved to be a useful indicator of CPX. Temporal and spatial studies using in situ hybridisation in both human and mouse has shown that TBX22/Tbx22 is expressed primarily in the palatal shelves and tongue during palatogenesis, indicating a specific role of TBX22 in both palatal and tongue development. ${ }^{19}{ }^{29}$ In addition to families with well defined $X$ linked inheritance, TBX22 mutations have been identified in several families where pedigree size and/or family history were too limited to predict mode of inheritance. $^{18} 19$ In these cases, ascertainment was largely based on the presence of ankyloglossia as well as cleft palate.

In this study, we investigated the prevalence of TBX22 mutations in a cohort of CP patients from different ethnic

\section{Key points}

- Cleft palate is a common birth defect, with a poorly understood molecular aetiology. Cleft palate with X linked inheritance (CPX) has been considered a rare form of the disorder, recently shown to result from mutations in the transcription factor TBX22.

- We analysed TBX22 in a large random sample of cleft palate patients with no pre-selection for inheritance or ankyloglossia, a common associated feature of CPX. We found coding mutations in 5/200 patients in North American and Brazilian cohorts, with an additional four putative splice site mutations.

- We also describe mutations in novel CPX families and present a combined phenotype/genotype analysis of the familial cases described to date. Males frequently exhibit cleft palate and ankyloglossia together (78\%), as do a smaller percentage of carrier females. Mutations within families can result in either cleft palate only, ankyloglossia only, or both, indicating that these defects are distinct parts of the phenotypic spectrum.

- We conclude that TBX22 is a significant risk factor for cleft palate. While ankyloglossia is not always present, a diagnosis of CPX is strongly supported by a positive family history and the tongue defect.

- Recognition of CPX in the complex pool of cleft palate patients will offer the potential for greatly improved genetic counselling.

backgrounds, who were randomly ascertained and were not selected on the basis of likely X linked inheritance or the cooccurrence of ankyloglossia. We also present several TBX22 mutations in new CPX families as well as an analysis of the phenotype-genotype correlations found in familial cases. Our findings suggest that $T B X 22$ mutations are responsible for a significant proportion of CP cases.

\section{MATERIALS AND METHODS}

\section{Patients}

Blood samples from 256 random or consecutive consenting CP patients were collected for DNA analysis from three geographically distinct populations: the Philippines, North America, and Brazil. Samples were obtained following informed consent with local ethical approval. The Filipino cohort are principally Asian, while the North American and

Abbreviations: $\mathrm{CL} / \mathrm{P}$, cleft lip or palate; $\mathrm{CP}$, cleft palate; $\mathrm{CPX}$, cleft palate with $\mathrm{X}$ linked inheritance 
Brazilian cohorts are of mixed origin, including white European and African descent. For each patient, a detailed phenotype was obtained, taking note of cleft type and associated features such as presence or absence of ankyloglossia and positive or negative family history. Syndromic features were described in 18 of the patients, the majority classified as Pierre-Robin syndrome (table 1). While the frequency of a positive family history is similar in different groups, the strikingly high incidence of ankyloglossia seen in the Brazilian cohort is notable. The general prevalence of ankyloglossia is not well documented, with reports varying from $0.04-5 \%{ }^{30}{ }^{31}$ Currently, it is not known whether the tongue defect is more common in the Brazilian population than elsewhere. Alternatively, this may reflect differences in diagnostic criteria or simply a regional difference local to the collection/treatment centres, where population frequencies may be skewed.

Two families with the characteristic CPX features of suspected $X$ linked inheritance and/or the presence of ankyloglossia were also analysed for TBX22 mutations. For family K, which is of white European origin, the proband presented with cleft palate only and had a brother with a cleft palate and a cousin with absent uvula. The mother and her sister both have ankyloglossia. The maternal grandfather was reported to have a cleft palate with ankyloglossia unknown. In family $\mathrm{W}$, also of white European origin, the proband presented with cleft palate and ankyloglossia and the family includes a further five affected males; one with absent tonsils (III.2) and two including ankyloglossia. Consistent with a semi-dominant X linked inheritance pattern, ankyloglossia was also observed in all obligate carrier females.

\section{Mutation analysis}

DNA was extracted from blood samples according to standard procedures. Each patient was examined for TBX22 variants following DNA sequencing of PCR amplified genomic fragments containing the flanking splice site junctions and exons $1-8$ as previously described. ${ }^{18}$ Sequence was analysed using Sequencher (version 4.1.2; Gene Codes Corporation, Ann Arbor, MI, USA). For each variant, normal controls (including Brazilian, white European, and Filipino) were screened to indicate whether the sequence was likely to represent a non-causative polymorphism. In addition, where DNA samples were available, parents or siblings were also screened for the same variant.

\section{RESULTS}

To establish whether TBX22 may contribute to the general causation of idiopathic CP, 256 cleft palate patients were screened for DNA mutations. No mutations were detected in any of the 18 syndromic patients within this cohort. In the remaining $238 \mathrm{CP}$ patients and controls, 15 different sequence variants were identified (table 2, fig 1). This included five potentially disease causing mutations affecting the coding region as well as several putative splice site mutations, none of which were present in control individuals. Four of the coding region mutations were found in patients with a positive family history for clefts and/or ankyloglossia and one in a patient with no known family history.

In the Brazilian $\mathrm{CP}$ group $(\mathrm{n}=102)$, four patients with mutations that directly affected the coding region were identified. These included a 2 bp deletion in exon 1 (105106delGC; numbering for all mutations found within the putative transcript starts at the adenine (A) residue of the ATG initiation codon) that results in a frameshift, potentially introducing a premature stop codon (fig 2). This male patient has both cleft palate and ankyloglossia but has no previous family history of clefting or tongue defects. Next, a single base substitution $(36 \mathrm{l} \rightarrow \mathrm{A})$ was identified in exon 3 in a
Table 1 Characteristics of cleft palate patients screened for TBX22 mutations

\begin{tabular}{lrlllllll}
\hline & \multicolumn{9}{c}{$\begin{array}{l}\text { Family } \\
\text { history }\end{array}$} & & & \\
\cline { 5 - 6 } $\begin{array}{l}\text { Origin of } \\
\text { patient }\end{array}$ & Male & Female & + ve & - ve & Syndromic* & CPO & CP+A \\
\hline USA & 40 & 65 & 28 & 77 & 11 & 102 & $3 \dagger$ \\
Brazil & 57 & 45 & $27 \ddagger$ & 75 & 0 & 64 & $38 \dagger$ \\
Philippines & 16 & 33 & $20 \S$ & 29 & 7 & 49 & 0 \\
Total & 113 & 143 & 75 & 181 & 18 & 215 & 41
\end{tabular}

*Includes putative Pierre-Robin syndrome (12), Stickler syndrome, chromosomal anomalies, Goldenhar-, and campomelic dysplasia-like syndromes; tincludes CP only probands with first degree relative with ankyloglossia as part of their phenotype; tincludes two pedigrees with male to male transmission; §includes four pedigrees with male to male transmission

familial male patient with ankyloglossia (fig 2). The mother and a maternal aunt both had ankyloglossia, while two maternal male cousins were reported to have cleft palate with ankyloglossia unknown. This resulting missense change (M121V) occurs at a position conserved throughout all $\mathrm{T}$ box genes and species. Finally, a 3 bp insertion (581582insCAG) introducing an additional serine residue was detected in two unrelated male patients (fig 2). One of these has an extended family history for clefts and ankyloglossia and was previously reported as a familial case. ${ }^{19}$ The other patient with cleft palate and ankyloglossia has a mother with the same phenotype but no additional family history. There is no known common ancestry between these two families for at least three generations; however, haplotype analysis with closely linked flanking markers demonstrated common alleles, possibly due to a founder effect (data not shown).

In the North American CP group $(\mathrm{n}=94)$, one missense mutation was identified. This was a single base transition $548 \mathrm{C} \rightarrow$ T resulting in an amino acid substitution P183L that was identified in a male patient with cleft palate only (fig 2). While the father of this patient was also reported to have cleft palate only, both the mother and maternal uncle have ankyloglossia. The proband cannot inherit TBX22 from the father and has inherited the mutation from the maternal $X$ chromosome. This position is highly conserved in $\mathrm{T}$ box genes and is based on the crystal structure of the Brachyury $\mathrm{T}$ domain. ${ }^{32}$ This lies within a $\beta$ barrel and corresponds to the putative site of contact for dimerisation. As is the case for all of the novel missense mutations described in this report, the position is conserved in mouse, rat, and chick Tbx22 (fig 3). It is likely therefore that this maternally inherited mutation significantly contributes to the phenotype of the proband.

In both the North American and Brazilian cohorts, a number of other single nucleotide alterations were detected (table 2). Several of these were identified multiple times either in patients alone, or in both patients and controls. The latter group is most likely to be non-causative polymorphisms, while a functional role of the former group cannot be excluded without further study. Of particular note, however, are two different sequence variants close to splice sites that were not seen in any of the unaffected controls studied. One is a potentially transcribed transversion $(-9 C \rightarrow G)$ that occurs immediately upstream of the translation start (ATG) codon (fig 2). This was present in two unrelated sporadic Brazilian male patients, both with ankyloglossia, but not in any other cleft palate individual or controls (table 2). Interestingly, the location of this change is ambiguous with respect to the transcript owing to the presence of an alternative $5^{\prime}$ exon. From $5^{\prime}$ RACE data, ${ }^{19}$ this mutation is located in the 5' UTR, 9 bp upstream of the start ATG. However, both the mouse and human EST databases contain 
Table 2 TBX22 sequence variants detected in 256 random CP patients

\begin{tabular}{|c|c|c|c|c|c|c|c|}
\hline \multirow[b]{2}{*}{ Mutation } & \multirow[b]{2}{*}{ Change } & \multirow{2}{*}{$\begin{array}{l}\text { Brazil } \\
(n=102)\end{array}$} & \multirow{2}{*}{$\begin{array}{l}\text { USA } \\
(n=105)\end{array}$} & \multirow{2}{*}{$\begin{array}{l}\text { Filipino } \\
(n=49)\end{array}$} & \multicolumn{3}{|c|}{ Control chromosomes } \\
\hline & & & & & Brazilian & European & Filipino \\
\hline$-9 C \rightarrow G$ & $5^{\prime} \cup T R / S p$ & 2 & 0 & 0 & $0 / 192$ & $0 / 104$ & $0 / 149$ \\
\hline $72 \mathrm{C} \rightarrow \mathrm{T}$ & L24L & 0 & 0 & 3 & $0 / 192$ & $0 / 104$ & $7 / 149$ \\
\hline 105-106 delGC & Frameshift & 1 & 0 & 0 & $0 / 192$ & $0 / 193$ & $0 / 149$ \\
\hline IVS1+41-42insA & Intronic & 1 & 0 & 0 & $0 / 192$ & $1 / 104$ & $0 / 149$ \\
\hline IVS1-13C $\rightarrow$ A & Intronic/sp & 0 & 2 & 0 & $0 / 70$ & $0 / 172$ & ND \\
\hline $361 \mathrm{~A} \rightarrow \mathrm{G}$ & M121V & 1 & 0 & 0 & $0 / 192$ & $0 / 104$ & ND \\
\hline IVS3+30G $\rightarrow$ A & Intronic & 0 & 1 & 0 & $0 / 192$ & ND & ND \\
\hline $548 \mathrm{C} \rightarrow \mathrm{T}$ & P183L & 0 & 1 & 0 & $0 / 143$ & $0 / 112$ & ND \\
\hline $559 \mathrm{G} \rightarrow \mathrm{A}$ & E187K & 7 & 7 & 0 & $8 / 143$ & $5 / 112$ & ND \\
\hline 581-582insCAG & S195-196ins & 2 & 0 & 0 & $0 / 143$ & $0 / 112$ & ND \\
\hline $883 \mathrm{~T} \rightarrow \mathrm{C}$ & L295L & 6 & 1 & 0 & $19 / 185$ & ND & ND \\
\hline IVS7+12T $\rightarrow G$ & Intronic & 0 & 0 & 0 & $2 / 185$ & ND & ND \\
\hline IVS7+56-57delC & Intronic & 8 & 1 & 17 & $16 / 185$ & ND & ND \\
\hline $1212 \mathrm{C} \rightarrow \mathrm{T}$ & $\mathrm{A} 404 \mathrm{~A}$ & 0 & 1 & 0 & $0 / 182$ & ND & ND \\
\hline $1591 \mathrm{~A} \rightarrow \mathrm{G}$ & 3'UTR & 0 & 0 & 1 & $0 / 182$ & ND & $2 / 102$ \\
\hline
\end{tabular}

sequences suggesting the presence of several different isoforms of TBX22 that use different upstream exons. ${ }^{19}$ These alternative transcripts utilise a splice site two bp upstream of the ATG, in which the $-9 \mathrm{C} \rightarrow \mathrm{G}$ mutation is intronic and located within five nucleotides of the AG splice sequence. The entire sequence containing the splice site and sequence variant is completely conserved between mouse and human (mouse CCCCTCCAGGGATG; human CCCCTCCAGGGATG) and the mutation was not seen in a total of 445 control chromosomes (table 2). The second variant is present in intron 1 , at IVS $1-13 \mathrm{C} \rightarrow \mathrm{A}$ and found in two sporadic CP only North American male patients. While the homology between the human and mouse sequence is not so strong as the $-9 \mathrm{C} \rightarrow \mathrm{G}$ variant (mouse: CCCCTGTCTAGCAG; human: TCTGTGTCCAGCAG), the sequence was also absent from normal chromosomes (table 2). Functional studies will be required to determine the significance of these changes.

Several coding region variants were identified (table 2), including a G559A transition that causes a missense glutamate to lysine (E187K) change within the $\mathrm{T}$ box motif. This amino acid position is variable in different $\mathrm{T}$ box genes and the base change was identified at a similar frequency (4-6\%) in both North American and Brazilian patients, as well as controls, but not in the Filipino cohort. Two other transcribed variants were detected, neither changing the potential peptide sequence. Variant $883 \mathrm{~T} \rightarrow \mathrm{C}$ within exon 7 does not change an amino acid (L295L) and corresponds to SNP rs195293 present in dbSNP (http://www.ncbi.nlm.nih.gov/ $\mathrm{SNP})$. This polymorphism was common in the Brazilian patients $(6 \%)$ and controls $(10 \%)$, but rarely in the North
American and Filipino groups. Variant $1212 \mathrm{C} \rightarrow \mathrm{T}$, corresponding to exon 8 , did not alter the peptide sequence (A404A) but was found only in a single North American patient and not in other patients or controls. Further SNPs were identified within intronic regions (table 2) and while rare, these were considered most likely to be non-causative.

In contrast to the genetically heterogeneous North American and Brazilian cohorts, no mutations were identified that were strongly suggestive of causation in the Filippino group. Nevertheless, three different single base substitutions were identified, including a common single base deletion, IVS7+56delC, and two changes that are transcribed but are not predicted to alter the mRNA or protein in an obvious way (table 2 ). The novel coding region variant $72 \mathrm{C} \rightarrow \mathrm{T}$ was found in three Filipino patients and in Filipino controls (7/149) but not in patients or controls of other ethnicities. This change does not alter the putative amino acid sequence (L24L) and most likely represents an ethnically or geographically restricted origin. Finally, one Filippino patient was heterozygous for a single base transition $(1591 \mathrm{~A} \rightarrow \mathrm{G}$ ) in exon 8 , which is 31 bp beyond the stop codon. This $3^{\prime}$ UTR sequence is well conserved (human acaattAcatgtaaaca; mouse acatttAcatgtaagca) and was not seen in other patient groups. However, the sequence variant was present in two unaffected Filipino controls (table 2), so while an effect on gene expression has yet to be ruled out, it is most likely a non-functional polymorphism.

In addition to previously reported families and the above patient groups, two new families were identified with possible X linked inheritance and/or presence of ankyloglossia (table 3 ). In each case, probands were screened for

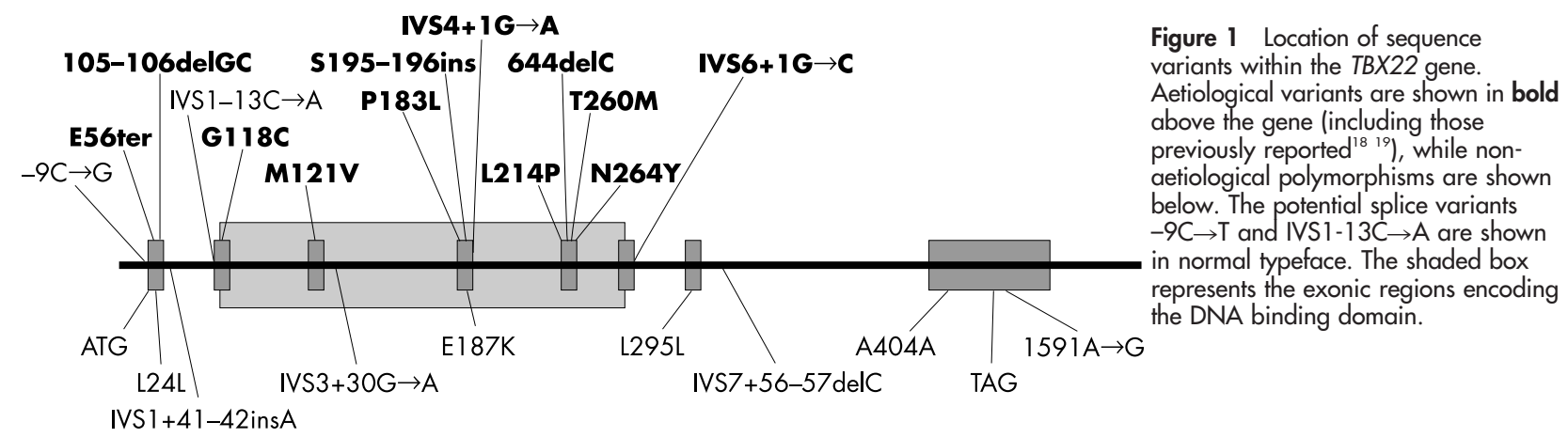

Figure 1 Location of sequence Aetiological variants are shown in bold above the gene (including those previously reported ${ }^{18}{ }^{19}$ ), while nonaetiological polymorphisms are shown below. The potential splice variants $-9 \mathrm{C} \rightarrow$ T and IVSI-13C $\rightarrow$ A are shown represents the exonic regions encoding 


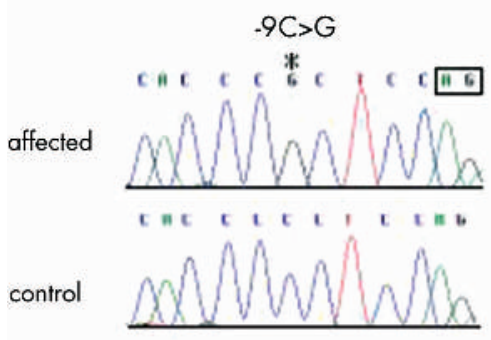

105-106 delGC

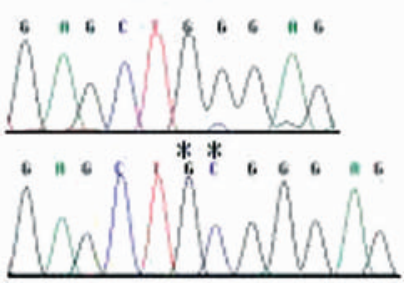

IVS1-13C>A

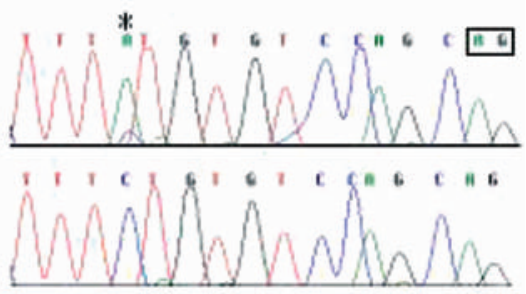

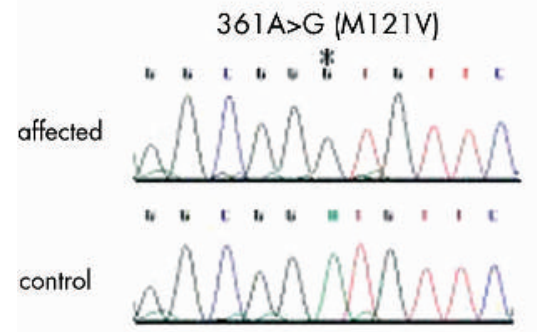
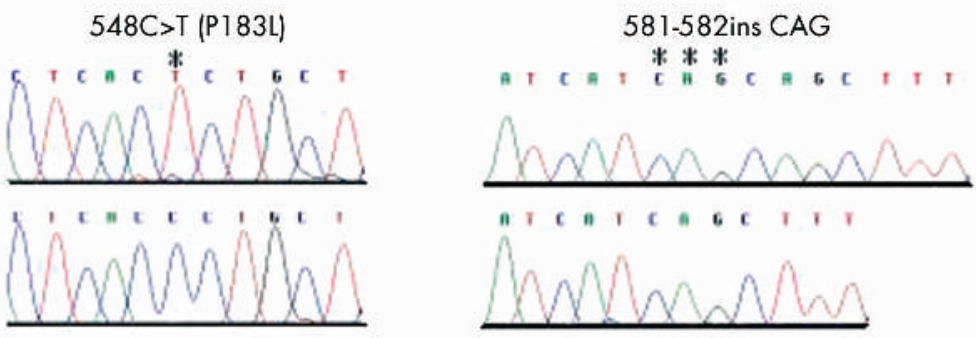

Figure 2 TBX22 mutations identified in randomly collected cleft palate patients. Sequence electropherograms are from patients' genomic DNA (top panels) amplified with exon specific primers and compared with unaffected control DNA samples (bottom panels). Boxed sequences represent 3' AG splice site sequences. *Represents the site(s) of the sequence variant.

mutations in TBX22 as described previously. The proband of family K presented with cleft palate only, but the presence of ankyloglossia in the mother was suggestive of the typical semi-dominant $X$ linked inheritance of CPX. An A786T transversion was detected in exon 5 , which is predicted to result in the missense mutation N264Y (fig 4). This amino acid position is located in the $\mathrm{T}$ box domain at the start of the alpha helix 3. This position recognises the target DNA in the minor groove and bridges the DNA backbone. ${ }^{32}$ The position is conserved throughout all $\mathrm{T}$ box genes and species available. The family history of family $\mathrm{W}$ also strongly indicated CPX and was found to have a $\mathrm{G} \rightarrow \mathrm{T}$ transversion at IVS4+1 (fig 4). This affects the invariant GT splice consensus sequence and is precisely the same variant identified in the Brazilian family BRl reported previously. ${ }^{18}$ Haplotype analysis with close flanking markers shows no other common alleles, indicating that these mutations arose independently (data not shown). Neither mutation was detected in >200 control chromosomes.

Ankyloglossia is a commonly associated feature found in X linked cleft palate and is frequently the only phenotype in carrier females. It has been regarded as an important diagnostic sign suggesting CPX in the absence of sufficient evidence for $X$ linked inheritance. ${ }^{19}$ We and others have previously shown that $T B X 22 / T b \times 22$ is specifically expressed both in the developing palatal shelves and future lingual frenulum during the time of palatogenesis. ${ }^{19}{ }^{29}$ As there is a reported correlation with the type and location of mutation within TBX5 and the clinical phenotype, ${ }^{33}$ we examined the concordance of palate and tongue phenotype with mutation

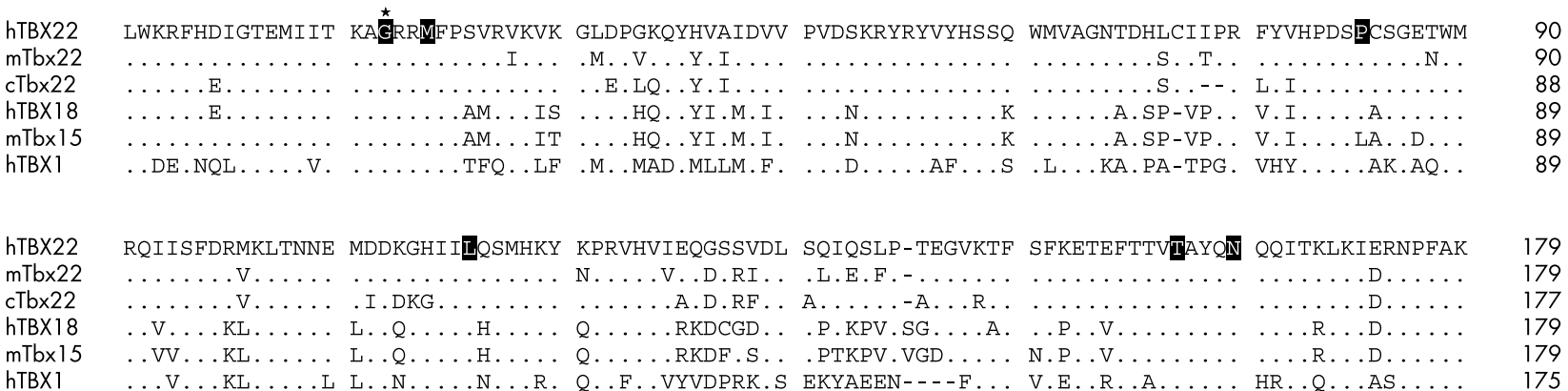

$\begin{array}{lll}\text { hTBX22 } & \text { GFRD } & 183 \\ \text { mTbx22 } & \ldots \ldots & 183 \\ \text { cTbx22 } & \ldots & 181 \\ \text { hTBX18 } & \ldots & 183 \\ \operatorname{mTb} 15 & \ldots & 183 \\ \text { hTBX1 } & \ldots . & 179\end{array}$

Figure 3 Clustal alignment of the T box domains of human (AAK63189), mouse (AAM64167) and chick (AAN09849) Tbx22. Also included are TBX1 (NP_542378), 15 (NP_689593) and 18 (O95935), which together with TBX22 represent an ancestral subgroup of T box proteins. ${ }^{40}$ The positions of missense mutations found in CP patients are marked in shaded boxes in the human TBX22 sequence. *Represents the Gly 80 residue in TBX5 that is mutated in a Holt-Oram syndrome patient. ${ }^{33}$ 
Table 3 TBX22 mutations in familial CP patients selected for analysis by $X$ linkage and/ or presence of ankyloglossia

\begin{tabular}{|c|c|c|c|c|c|}
\hline Family & Selection* & Mutation & Exon & Effect & Reference \\
\hline London & $A$ & $166 \mathrm{G} \rightarrow \mathrm{T}$ & 1 & E56X stop codon & 18 \\
\hline Mennonite & $\mathrm{X}+\mathrm{A}$ & $352 \mathrm{G} \rightarrow \mathrm{T}$ & 2 & G118C missense & 18 \\
\hline Family 2 (BR3) & A & 581-582insCAG & 4 & S195-196ins & 19+text \\
\hline BRI & $X+A$ & IVS4+1G $\rightarrow$ A & 4 & Splice site & 18 \\
\hline Family W & $A$ & IVS4+1G $\rightarrow$ A & 4 & Splice site & See text \\
\hline Family 1 & A & $641 \mathrm{~T} \rightarrow \mathrm{C}$ & 5 & L21 $4 \mathrm{P}$ missense & 19 \\
\hline BR2 & $X+A$ & 664 delC & 5 & Frame shift & 18 \\
\hline Native American & $\mathrm{X}+\mathrm{A}$ & $779 \mathrm{C} \rightarrow \mathrm{T}$ & 5 & T260M missense & 18 \\
\hline Family K & $A$ & $790 \mathrm{~A} \rightarrow \mathrm{T}$ & 5 & N264Y & See text \\
\hline Icelandic & $\mathrm{X}+\mathrm{A}$ & IVS6+1G $\rightarrow C$ & 6 & Splice site & 18 \\
\hline
\end{tabular}

type in familial cases where genotype data were available for multiple family members. Data were collated from 13 unrelated CPX families, including the large Icelandic family, ${ }^{18} 28$ which is also presented separately to illustrate the phenotypic variability despite a similar genetic background (table 4). Overall, males carrying mutations (96\%) exhibited cleft palate or a microform of cleft palate as the primary phenotype regardless of mutation type. Within this group, a range of severity was seen within the larger families, which included complete cleft of the secondary palate, submucous cleft, bifid uvula, absent tonsils, or high vaulted palate. Ankyloglossia is seen in $79 \%$ of male patients but is present as the sole phenotype in only $4 \%$. Ankyloglossia is a common phenotype $(45 \%)$ in female carriers but cleft palate $(6 \%)$ may also be the sole presenting feature.

\section{DISCUSSION}

Despite the high degree of heterogeneity responsible for human CP, the sequence changes in TBX22 reported here provide the first evidence that $X$ linked cleft palate makes an important contribution to the general prevalence of orofacial clefting. The mutation types included frameshift and splice site changes, which resulted either in truncated proteins or rapid removal of transcripts through the mechanism of nonsense mediated decay, but also a number of missense mutations that only affected single amino acids within the DNA binding $\mathrm{T}$ box domain. From the predicted three dimensional structure elucidated for both $\mathrm{T}$ and TBX3, ${ }^{32}{ }^{34}$ it is likely that these variants interfere with the capability of the
Table 4 Phenotypic variation found within CPX families

\begin{tabular}{lcccc}
\hline Gender & CPA $^{*}$ & CPO* $^{*}$ & AO & Unaffected \\
\hline Icelandic male $(n=28)$ & $21(75 \%)$ & $6(21 \%)$ & $1(3 \%)$ & $0(0 \%)$ \\
Total male $(n=87) \dagger$ & $69(79 \%)$ & $14(17 \%)$ & $3(4 \%)$ & $0(0 \%)$ \\
Icelandic female $(n=37)$ & $3(8 \%)$ & $1(3 \%)$ & $23(62 \%)$ & $10(27 \%)$ \\
Total female $(n=101) \dagger$ & $11(11 \%)$ & $5(6 \%)$ & $45(45 \%)$ & $38(38 \%)$ \\
\hline
\end{tabular}

*Cleft phenotype includes cleft of the hard and soft palate, cleft of the soft palate, bifid or absent uvula, or high arched palate.

tData obtained from individuals carrying mutations in 13 independent families.

protein either to bind DNA or to form stable interactions, perhaps as dimers or with other binding proteins in the transcriptional complex. Similar findings have been reported for other $\mathrm{T}$ box gene mutations such as those found in $T B X 3$ and TBX5 and TBX19. ${ }^{35-37}$ In addition, missense mutations in TBX5 were all shown to result in impaired nuclear localisation and it is thought that this too may contribute to the loss of transcriptional activation function. ${ }^{38}$

Interestingly, one $T B X 22$ mutation $\left(\mathrm{Gl}_{18 \mathrm{C}^{18}}\right)$ corresponds to the equivalent TBX5 T box domain amino acid position Gly 80 that is mutated (G80R) in a Holt-Oram syndrome patient. ${ }^{33}$ This position is predicted to interact with the major groove of target DNA and has been shown to result in loss of DNA binding. ${ }^{38}{ }^{39}$ This is similar to the majority of TBX22 missense mutations that occur at points of contact with the

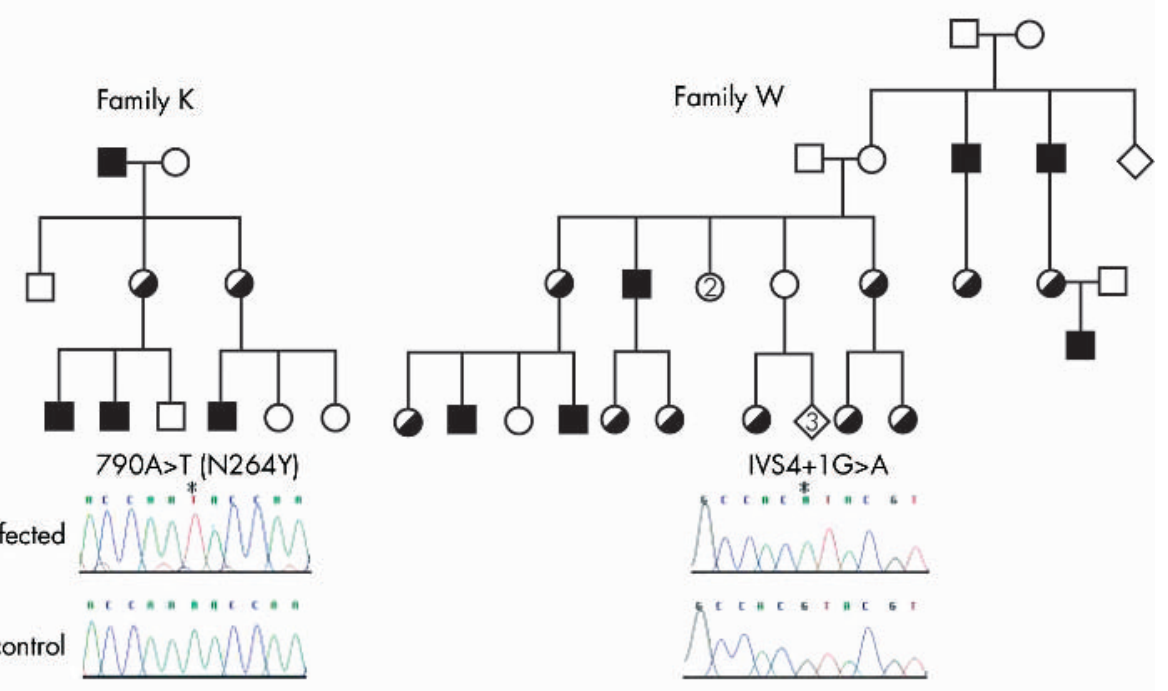

Figure 4 TBX22 mutations in two families predicted to have $X$ linked cleft palate and ankyloglossia. Sequence electropherograms from genomic DNA amplified from exon 5 (family K) and exon 4 (family W) are of affected (mutant) males and unaffected (control) females. *Represents the site of the sequence variant. 
DNA backbone. In contrast, one TBX5 missense mutation Gl69R, found within the T box domain does not affect DNA binding but causes diminished interaction between TBX5 and NKX2.5, reducing synergy during transcriptional activation. ${ }^{38}$ This location is within four residues of the previously described Leu 214 mutation $^{19}$ and may also be involved in forming essential molecular interactions within the transcriptional complex. In addition, the P183L TBX22 mutation described in this report has the potential for a role in proteinprotein interaction rather than protein-DNA contact. This position is equivalent to the Pro 128 in Xenopus Brachury, which forms part of a small hydrophobic region thought to be the interface for dimerisation..$^{32}$ There is currently debate as to whether $\mathrm{T}$ box genes actually do dimerise in vivo, as they are stable as monomers in solution and the palindromic binding sequence elucidated for Brachyury has not been observed in the downstream targets identified so far. Prol83 is highly conserved within $\mathrm{T}$ box proteins and between species, although it is interesting to note that an exception is TBX15, where a leucine residue is present. From an evolutionary perspective, TBX15 is closely related to TBX22, ${ }^{40}$ sharing a common ancestoral sequence Tbx15/18/ 22 in the cephalochordate Amphioxus, which is the closest living invertebrate relative of the vertebrates. ${ }^{41}$ It will be important to investigate the role of this protein region in terms of homo- or hetero-dimerisation and other proteinprotein interactions, which may contribute to the functional specificity found between similar $\mathrm{T}$ box genes. ${ }^{32}{ }^{42}$

The evidence suggests that whether missense or nonsense, the effect of the mutations is most likely to be a loss of functional protein and in males, this is highly penetrant for a cleft. From the families studied, there was no evidence that different types of mutation or location of the missense mutations had a significant role in determining the severity or specificity of the phenotype. The variable expression of CPX is therefore likely to be influenced by modifiers or environmental factors. It is interesting to note that the portion of the CPX family living in the north of Iceland generally has a milder phenotype than those living in the south. ${ }^{28}$ Not surprisingly, heterozygous females share greater variability in their phenotype and it is equally likely they will have ankyloglossia only or no phenotype at all. Not all female carriers escape a cleft, however, which affects $16 \%$ regardless of tongue phenotype. It is not yet clear whether this variability is the result of non-random $\mathrm{X}$ inactivation or due to the later closing of the female palate in human development. ${ }^{43}$ The combined male and female data suggest that while ankyloglossia is a common phenotype associated with TBX22 mutations, its occurrence is not a prerequisite for cleft palate and the two features are independent effects of loss of TBX22 function.

TBX22 clearly makes a significant contribution to the prevalence of cleft palate and it will be important to study its biological role in the process of craniofacial development. Owing to its role as a transcription factor that is expressed specifically in tissues related to palatogenesis and its confirmation as a major genetic influence in normal palate development, identification of the downstream target genes remains a priority. Although causative mutations lying outside of the exonic regions screened in this study may play a part, it seems extremely likely that the CPA patients lacking TBX22 mutations will harbour mutations in other genes that function in the same transcriptional pathway. Characterisation of the gene networks in which TBX22 participates will therefore identify novel candidate genes and provide important insights into the mechanisms involved during palatogenesis.

As more and more of the genes contributing to facial clefting disorders become characterised, the ability to make informed counselling decisions is greatly improved. There is often a very fine division between orofacial clefts that can be truly categorised as non-syndromic and those that are syndromic, particularly where associated features are often mild and variable in their expression. As is shown in this report, the elucidation of single gene disorders will show increasing overlap between the two. While in general, DNA sequencing of unselected $\mathrm{CP}$ patients may not yet be a realistic option, screening of patients with a positive family history and/or ankyloglossia may be worthwhile. Our experience shows that the majority of familial cases with suspected CPX and up to $4 \%$ of unselected CP cases have TBX22 mutations. For each patient harbouring a mutation, recurrence risk assessment is substantially enhanced from an empiric $3-5 \%$ to a more informative $25-50 \%$. In combination with a better understanding of the cellular biology, this will lead to appropriate advice, therapy, and ultimately prevention.

\section{ACKNOWLEDGEMENTS}

We are extremely grateful to the patients, families, and clinicians who participated in this study and acknowledge the expert assistance of A Arnason and A Bjornsson. We appreciate the technical support from C Roberto De Oliveira, A Davies, S Newman, A Crosby, K Krahn and S Daack-Hirsch. We also wish to thank CNPq for funding the Brazilian DNA sample collection and NIH grant DE08559 (JCM) for funding the collection of samples in the Philippines. In addition, this work was generously funded by the Birth Defects Foundation, Hammersmith Hospital Trust Research Committee, and Professor Lord Robert Winston.

\section{Authors' affiliations}

A C B Marçano, K Doudney, C Braybrook*, G E Moore, P Stanier, Institute of Reproductive and Developmental Biology, Imperial College London, Du Cane Road, London W12 ONN, UK

R Squires, M A Patton, M M Lees, Medical Genetics Unit, St George's Hospital Medical School, Tooting, London SW17 ORE, UK

A C B Marçano, A Richieri-Costa, Hospital de Reabilitação de Anomalias Craniofaciais, Universidade de São Paulo, Bauru, São Paulo, Brazil

A C Lidral, Department of Orthodontics, University of lowa, IA, USA

J C Murray, Department of Pediatrics, University of lowa, IA, USA

*Present address: Molecular Medicine Unit, Institute of Child Health, 30 Guildford Street, London WCIN 1EH, UK

Correspondence to: DrP Stanier, 4th Floor, Institute of Reproductive and Developmental Biology, Imperial College London, Du Cane Road, London, W12 ONN, UK; pstanier@imperial.ac.uk

Received 2 June 2003

Accepted 26 August 2003

\section{REFERENCES}

1 Bender PL. Genetics of cleft lip and palate. J Pediat Nurs 2000;15:242-9.

2 Sharpe PM, Ferguson MWJ. Mesenchymal influences on epithelial differentiation in developing systems. J Cell Sci 1988;10(Suppl):195-230.

3 Cuervo R, Valencia C, Chandraratna RAS, Covarrubias L. Programmed cell death is required for palate shelf fusion and is regulated by retinoic acid. Dev Biol 2002; 245:145-56.

4 Fogh-Anderson P. Inheritance of harelip and cleft palate. Copenhagen: Munksgaard, 1942.

5 Fraser FC. The genetics of cleft lip and palate: yet another look. In: Pratt RM, Christiansen KL, eds. Current research trends in prenatal craniofacial development 1980:357-366.

6 Farrall M, Holder S. Familial recurrence-pattern analysis of cleff lip with or without cleft palate. Am J Hum Genet 1992;50:270-7.

7 Schliekelman P, Slatkin M. Multiplex relative risk and estimation of the number of loci underlying an inherited disease. Am J Hum Genet 2002;71:1369-85.

8 Prescott NJ, Winter RM, Malcolm S. Nonsyndromic cleft lip and palate: complex genetics and environmental effects. Ann Hum Genet 2001;65:505-15.

9 Spritz RA. The genetics and epigenetics of orofacial clefts. Curr Opin Pediatr $2001 ; 13: 556-60$.

10 Prescott NJ, Lees MM, Winter RM, Malcolm S. Identification of susceptibility loci for nonsyndromic cleft lip with or without cleft palate in a two stage genome scan of affected sib-pairs. Hum Genet 2000;106:345-50. 
11 Marazita ML, Field LL, Cooper ME, Tobias R, Maher BS, Peanchitlertkajorn S, Liu YE. Genome scan for loci involved in cleft lip with or without cleft palate, in Chinese multiplex families. Am J Hum Genet 2002;71:349-64.

12 Murray JC. Gene/environment causes of cleft lip and/or palate. Clin Genet 2002;61:248-56.

13 Wilkie AO, Morriss-Kay GM. Genetics of craniofacial development and malformation. Nat Rev Genet $2001 ; 2: 458-68$.

14 Sozen MA, Suzuki K, Talavora MM, Bustos T, Fernandez Iglesias JE, Spritz RA. Mutation of PVRL1 is associated with sporadic, non-syndromic cleft lip/palate in northern Venezuela. Nat Genet 2001;29:141-2.

15 Van den Boogard M-JH, Dorland M, Beemer FA, Ploos van Amstel HK. MSX1 mutation is associated with orofacial clefting and tooth agenesis in humans. Nat Genet 2000;24:342-3.

16 Jezewski P, Vieira A, Schultz R, Machida J, Suzuki Y, Ludwig B, DaackHirsch S, O'Brian S, Nishimura C, Johnson M, Murray JC. Mutations in MSX1 are associated with non-syndromic orofacial clefting. J Med Genet 2003;40:399-407

17 Kondo S, Schutte BC, Richardson RJ, Biork BC, Knight AS, Watanabe Y, Howard E, de Lima RL, Daack-Hirsch S, Sander A, McDonald-McGinn DM Zackai EH, Lammer EJ, Aylsworth AS, Ardinger HH, Lidral AC, Pober BR, Moreno L, Arcos-Burgos M, Valencia C, Houdayer C, Bahuau M, MorettiFerreira D, Richieri-Costa A, Dixon MJ, Murray JC. Mutations in IRF6 cause Van der Woude and popliteal pterygium syndromes. Nat Genet 2002;32:285-9.

18 Braybrook C, Doudney K, Marçano ACB, Arnason A, Bjornsson A, Patton MA, Goodfellow PJ, Moore GE, Stanier P. The T-box transcription factor gene TBX22 is mutated in X-linked cleft palate and ankyloglossia. Nat Genet 2001;29:179-83.

19 Braybrook C, Lisgo S, Doudney K, Henderson D, Marçano ACB, Strachan T, Patton MA, Villard L, Moore GE, Stanier P, Lindsay S. Craniofacial expression of human and murine TBX22 correlates with the cleft palate and ankyloglossia phenotype observed in CPX patients. Hum Mol Genet 2002; 11:2793-804.

20 Lowry RB. Sex linked cleft palate in a British Columbian Indian family. Pediatrics 1970;46:123-8

21 Rushton AR. Sex linked inheritance of cleft palate. Hum Genet 1979:48:179-181.

22 Rollnick BR, Kaye Cl. Mendelian inheritance of isolated nonsyndromic cleft palate. Am J Med Genet 1986;24:465-73.

23 Bixler D. Letter to the editor: X-linked cleft palate. Am J Med Genet 1987;26:503-5.

24 Hall BD. Letter to the editor: A further X-linked isolated nonsyndromic cleft palate family with a nonexpressing obligate affected male. Am J Med Genet 1987;26:239-40

25 Moore GE, Ivens A, Chambers J, Farral M, Williamson R, Bjornsson A, Arnason A, Jensson O. Linkage of an X-chromosome cleft palate gene. Nature 1987;326:91-2.

26 Gorski SM, Adams KJ, Birch PH, Chodirker BN, Greenberg CR, Goodfellow PJ. Linkage analyses of X-linked cleft palate and ankyloglossia in Manitoba Menonite and British Columbia Native kindreds. Hum Genet 1994;94:141-8.
27 Marçano ACB, Ming JE, Du YZ, George RA, Ryan SG, Richieri-Costa A, Muenke M. X-linked cleft palate and ankyloglossia: refinement of the minimal critical region in Xq21.3. Am J Hum Genet 2001;69(Suppl):2606.

28 Bjornsson A, Arnason A, Tippet P. X-linked midline defect in an Icelandic family. Cleft Palate J 1989;26:3-8.

29 Bush JO, Lan Y, Maltby KM, Jiang R. Isolation and developmental expression analysis of Tbx22, the mouse homolog of the human X-linked cleft palate gene. Dev Dyn 2002;225:322-6.

30 Messner AH, Lakea ML, Aby J, Macmahon J, Blair E. Ankyloglossia: incidence and feeding difficulties. Arch Otolaryngol Head Neck Surg 2000;126:36-9.

31 Warden PJ. Ankyloglossia: A review of the literature. Gen Dentistry $1991 ; 39: 252-253$

32 Müller CW, Herrmann BG. Crystallographic structure of the T domain-DNA complex of the Brachyury transcription factor. Nature 1997;389:884-8.

33 Basson CT, Huang T, Lin RC, Bachinsky DR, Weremowicz S, Vaglio A, Bruzzone R, Quadrelli R, Lerone M, Romeo G, Silengo M, Pereira A, Krieger J, Mesquita SF, Kamisago M, Morton CC, Pierpont ME, Muller CW, Seidman JG, Seidman CE. Different TBX5 interactions in heart and limb defined by HoltOram syndrome mutations. Proc Natl Acad Sci USA 1999:96:2919-24.

34 Coll M, Seidman JG, Muller CW. Structure of the DNA-bound T-box domain of human TBX3, a transcription factor responsible for ulnar-mammary syndrome. Structure 2002;10:343-56.

35 Bamshad $M$, Lin RC, Law DJ, Watkins WS, Krakowiak PA, Moore ME, Franceschini B, Lala R, Holmes LB, Gebuhr TC, Bruneau BG, Schinzel A Seidman JG, Seidman CE, Jorde LB. Mutations in human TBX3 alter limb, apocrine and genital development in ulnar-mammary syndrome. Nat Genet 1997; 16:311-15.

36 Basson CT, Backinscky DR, Lin RC, Levi T, Elkins JA, Soults J, Grayzel D, Kroumpousou K, Trail TA, Leblanc-Straceski J, Renault B, Kucherlapati R, Seidman JG, Seidman CE. Mutations in human TBX5 cause limb and cardiac malformations in Holt-Oram syndrome. Nat Genet 1997;15:30-5.

37 Lamolet B, Pulichino AM, Lamonerie T, Gauthier Y, Brue T, Enjalbert A Drouin J. A pituitary cell-restricted T box factor, Tpit, activates POMC transcription in cooperation with Pitx homeoproteins. Cell 2001;104:849-59.

38 Fan $C$, Liu $M$, Wang $Q$. Functional analysis of TBX5 missense mutations associated with Holt-Oram syndrome. J Biol Chem 2003;278:8780-5.

39 Ghosh TK, Packham EA, Bonser AJ, Robinson TE, Cross SJ, Brook JD. Characterization of the TBX5 binding site and analysis of mutations that cause Holt-Oram syndrome. Hum Mol Genet 2001; 10:1983-94.

40 Ruvinsky I, Silver LM, Gibson-Brown JJ. Phylogenetic analysis of T-box genes demonstrates the importance of Amphioxus for understanding evolution of the vertebrate genome. Genetics 2000;156:1249-57.

41 Wada H, Satoh N. Details of the evolutionary history from invertebrates to vertebrates, as deduced from the sequences of $18 \mathrm{~S}$ rDNA. Proc Natl Acad Sci USA 1994;91:1801-84.

42 Conlon FL, Fairclough L, Price BMJ, Casey ES, Smith JC. Determinants of T box protein specificity. Development 2001;128:3749-58

43 Burdi A, Silvey R. Sexual differences in closure of the human palatal shelves. Cleft Palate J 1969;6:1-7.

\section{CORRECTION}

We would like to apologise for a number of errors that were published online in the paper by Kohlhase et al, (J Med Genet 2003;40:e127). R276X was incorrectly referred to as ArgR276X throughout the first page of the article. In addition, the first sentence of the second paragraph of the paper should read: Twenty three of 24 SALLI mutations known to date are located in exon $2\left(^{25-11}\right.$ and unpublished results). 